American Journal of Applied Sciences 1 (4): 316-320, 2004

ISSN 1546-9239

(C) Science Publications, 2004

\title{
Finite Difference Solution for Precooling Process of Fish Packages
}

\author{
K.A. Abbas, F.A. Ansari, \\ A.S. Mokhtar, A.O. Ashraf, M.A. Wan and S.M. Sapuan \\ Faculty of Engineering, \\ Universiti Putra Malaysia, 43400 Serdang Selangor Darul Ehsan, Malaysia
}

\begin{abstract}
The present work aims at finding an optimized finite difference scheme for the solution of problems involving pure convection heat transfer in slab shaped fresh water fish pieces. A generalized mathematical model was written in dimensionless form and an optimized scheme of the solutions was worked out. A fully explicit finite difference scheme, an implicit finite difference scheme and different combination of the two, with varying values of the weighing factor were thoroughly studied. All the possible options of temperature-time grid sizes were considered. It was found that the simplest explicit finite difference scheme with ten characteristic length division and Fourier number increments one sixth of the square of the space division size gives best convergence and minimal truncation error. Numerically computed and measured temperature-time variations were found to have excellent agreement.
\end{abstract}

Key words: Finite Difference Scheme, Freshwater Fish, Heat Transfer, Optimized Scheme

\section{INTRODUCTION}

Cooling is a common and important fish preservation technique and it is used to maintain the quality and inhibiting the spoilage of the product. Transient heat transfer may play an important role in food-cooling applications. The most complicated heat transfer problems are successfully solved by using either finite difference or finite element techniques ${ }^{[1]}$. These numerical methods are capable of handling any type of boundary condition and product geometry. Any nonlinearity or singularity can also be handled and changes of thermo physical properties, if any, can be incorporated. In the present work the particular application of interest is the precooling of Malaysian Pangasius sutchi fish packages exposed to a chilled air stream.

This species of freshwater fish are extensively used as a food in Malaysia ${ }^{[2]}$, nevertheless no publications are available regarding the thermal properties and heat transfer analysis during heating and cooling of this important fish species ${ }^{[3]}$. During its precooling, the fish is cooled after catching, so that its temperature is quickly brought to the cold storage temperature. This enables the refrigeration engineer to select a smaller size of heat transfer equipment for the cold storage warehouse. During the precooling process, the only convective heat transfer takes place for packaged food. Because of its relative simplicity, the finite difference method is more popularly used to solve the transient heat transfer problems related to food processors. By applying the numerical grid generation approach, it can be used for irregular geometry as effectively as the more complicated finite element method, without sacrificing its simplicity. A number of investigators have used finite difference methods for solving problems with pure convective heat transfer from the surface of food products. Major works are those reported by ${ }^{[1,4-8]}$. These models give satisfactory results during air blast cooling of wrapped, packaged or tinned foods or during hydro cooling.

Several finite difference schemes have been described in the solution of transient heat conduction equations with different initial and boundary conditions $^{[9-11]}$. The present work deals with thorough comparative investigations of the fully explicit scheme, fully implicit scheme and different weighted averages of the two schemes, so as to establish the scheme which is best suited for computing temperature-time variations during precooling of the slab shaped freshwater fish packages with pure convection heat transfers.

Mathematical formulations: The normalized transient heat conduction equation for isotropic solids in which heat transfer may be approximated to be unidirectional and there is no internal heat generation is described as follows $^{[1,12]}$.

$\frac{1}{\mathrm{x}^{\mathrm{m}}} \frac{\partial}{\partial \mathrm{x}}\left(\mathrm{x}^{\mathrm{m}} \frac{\partial \mathrm{U}}{\partial \mathrm{x}}\right)=\frac{\partial \mathrm{U}}{\partial \tau}$ for $\tau \geq \tau_{\mathrm{O}} 0 \leq \mathrm{X} \leq 1$

where, $\mathrm{m}=0$ for an infinite slab, 1 for an infinite cylinder and 2 for a sphere. If the product is initially at a uniform temperature and symmetrical cooling occurs, the initial condition and center boundary condition are defined, respectively, by the following equations

$$
\begin{aligned}
& U=U(X) \tau=\tau_{0} 0 \leq X \leq 1 \\
& \frac{\partial U}{\partial X}=0 \text { for } \tau>\tau_{0} X=0
\end{aligned}
$$


At the surface, the pure convection boundary condition is defined by the Eq. 4 :

$\frac{\partial \mathrm{U}}{\partial \mathrm{X}}=-\mathrm{BiU}$ for $\tau>\tau_{\mathrm{O}} \mathrm{X}=1$

The general finite difference representation of the governing heat conduction equation (1) is given as follows ${ }^{[9]}$ :

$$
\begin{aligned}
& \frac{\mathrm{U}_{\mathrm{i}}^{\mathrm{j}+1}-\mathrm{U}_{\mathrm{i}}^{\mathrm{j}}}{\Lambda \tau}=\frac{\theta}{(\Lambda \mathrm{X})^{2}}\left[(1-\mathrm{Y}) \mathrm{U}_{\mathrm{i}-1}^{\mathrm{j}+1}-2 \mathrm{U}_{\mathrm{i}}^{j+1}+\right. \\
& \left.(1+\mathrm{Y}) \mathrm{U}_{\mathrm{i}-1}^{j+1}\right]+\frac{(1-\theta)}{(\Lambda \mathrm{X})^{2}}\left[(1-\mathrm{Y}) \mathrm{U}_{\mathrm{i}-1}^{\mathrm{j}}-2 \mathrm{U}_{\mathrm{i}}^{\mathrm{j}}+(1-\mathrm{Y}) \mathrm{U}_{\mathrm{i}+1}^{\mathrm{j}}\right]
\end{aligned}
$$

where, subscript " $\mathrm{i}$ " and superscript " $\mathrm{j}$ " in the above finite difference representation stand for space and time step, respectively:

$$
\Lambda \mathrm{X}=\frac{1}{\mathrm{n}}
$$

$\Delta \tau=$ size of the normalized time step

$\mathrm{Y}=0$ for slab

$\mathrm{Y}=\frac{1}{2 \mathrm{i}}$ for cylinder

$\mathrm{Y}=\frac{1}{\mathrm{i}}$ for sphere

$\theta$ is the weighing factor, which is 0 for explicit scheme, 1 for the fully implicit scheme and for general implicitexplicit scheme, $\theta$ is given as:

$0<\theta<1$

For higher computational accuracy, the first derivatives in the center and surface boundary condition equations are written in the form of the four-point formulae ${ }^{[13]}$, given, respectively as below:

$$
\begin{aligned}
& \frac{\partial U}{\partial X}=\frac{1}{6 \Lambda X}\left(-11 U_{o}^{j+1}+18 U_{1}^{j+1}\right. \\
& \left.-9 U_{2}^{j+1}+2 U_{3}^{j+1}\right) \text { for } \mathrm{X}=0 \\
& \frac{\partial U}{\partial X}=\frac{1}{6 \Delta X}\left(-2 U_{n-3}^{j+1}+\right. \\
& \left.9 U_{n-2}^{j+1}-18 U_{n-1}^{j+1}+11 U_{n}^{j+1}\right) X=1
\end{aligned}
$$

Equations (12) and (13) are based on Lagrangian interpolation and are reported to have a truncation error $\mathrm{O}(\Delta \mathrm{X})^{3}$.
Experimental procedure: In the present work, experimental and theoretical investigations were carried out on a slab shaped sample of fresh water Pangasius sutchi Malaysian fish. The work was started firstly with mass density measurement by means of electronic balance with resolution of $0.001 \mathrm{~g}$. The volume was measured by dipping the sample in a calibrated jar filled with water. The measurement of water content of the fish sampled was made by a sensitive electronic balance fitted with infrared dryer set at $105{ }^{\circ} \mathrm{C}$ for 12 hours. A mass of thinly cut fish pieces was determined before and after thorough drying until no further moisture loss was obtained. With the measured value of the water mass fraction $(\mathrm{W})$, its thermal conductivity was determined by Sweat correlation ${ }^{[14]}$ :

$\mathrm{k}=0.08+0.52 \mathrm{~W}$

The specific heat was determined by Reidel's model for fish meat above freezing point as given below $^{[15]}$ :

$\mathrm{Cp}=1.672+2.508 \mathrm{~W}$

The coefficient of heat transfer was calculated by $\mathrm{Nu}$ - Re relationship given below ${ }^{[1]}$ :

$\mathrm{Nu}=\mathrm{p}+\mathrm{qRe} \mathrm{e}^{\mathrm{r}} \mathrm{Pr}^{\mathrm{s}}$

The air-blast cooling duct, its test section, rectangular shaped fish piece containers and related instrumentation have been explained elsewhere ${ }^{[16]}$. The temperature of the circulating air inside the test duct was maintained constant at $1{ }^{\circ} \mathrm{C}$ and the velocity of air passing over the test container was kept constant throughout the experiments at $6 \mathrm{~m} / \mathrm{s}$. Five copperconstantan thermocouple beads were installed inside the fish flesh, at the depths $\mathrm{x}_{0} / 5,2 \mathrm{x}_{0} / 5,3 \mathrm{x}_{0} / 5,4 \mathrm{x}_{0} / 5$ and $\mathrm{x}_{0}$ from the sample surface. In order to insert the temperature sensors at the desired depths, five fine holes were drilled at equal distances of $5 \mathrm{~mm}$ from each other in the middle of one copper sheet cover of the test container. The lead wires of all the thermocouples were connected with a data logger. The temperatures were recorded at a specified equal time interval of 1 minute while each experiment lasted for 60 minutes. First the refrigeration system of the chilling duct was run until a constant temperature of $1{ }^{\circ} \mathrm{C}$ was achieved. Then the fish package was suspended in the test section of the air duct such that the conducting surfaces were parallel to the direction of flow of the chilled air stream. The data logger was used to collect the transient temperature time data.

Computational procedure: The system of equations (1-13) was solved for predicting temperature time variations during cooling of fish packages with pure convection heat transfer from their surface. The coordinate system for the fish package is shown in Fig. 
1 and the mesh of time and space intervals during the finite difference solutions are shown in Fig. 2. First of all, measured thermo physical properties and a sample set of temperature-time records were chosen to establish the best calculation scheme. The measured and estimated thermo physical properties of Pangasius sutchi fish are listed in Table 1.

The experimental results for this slab shaped sample during its air blast cooling, considering only heat transfer, were compared to all the possible implicit finite difference schemes. The concept of least root means square method of the error has been used which is defined as:

Table 1: Data for precooling of a slab shaped fish sample

\begin{tabular}{lllc}
\hline Parameter & Notation & Units & $\begin{array}{l}\text { Numerical } \\
\text { value }\end{array}$ \\
\hline $\begin{array}{l}\text { Specific heat capacity } \\
\text { Surface heat transfer }\end{array}$ & $\mathrm{c}_{\mathrm{p}}$ & $\mathrm{kJ} / \mathrm{kg} . \mathrm{K}$ & 3.75364 \\
Coefficient & $\mathrm{h}$ & $\mathrm{W} / \mathrm{m}^{2} . \mathrm{K}$ & 78.99 \\
Thermal conductivity & $\mathrm{k}$ & $\mathrm{W} / \mathrm{m} . \mathrm{K}$ & 0.5296 \\
Dry bulb temperature & $\mathrm{T}_{\mathrm{db}}$ & ${ }^{\circ} \mathrm{C}$ & 1 \\
Initial temperature & $\mathrm{T}_{\mathrm{i}}$ & ${ }^{\circ} \mathrm{C}$ & 25 \\
Half slab thickness & $\mathrm{x}_{0}$ & $\mathrm{~m}$ & 0.0127 \\
Mass density & $\rho$ & $\mathrm{kg} / \mathrm{m}^{3}$ & 1052 \\
Relative humidity of air & $\varnothing$ & $\%$ & $90 \%$ \\
\hline
\end{tabular}

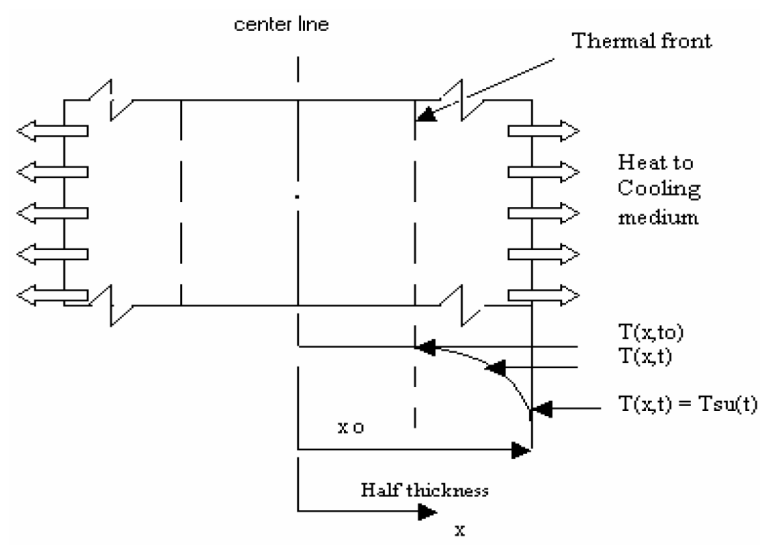

Fig. 1: Coordinate system during precooling

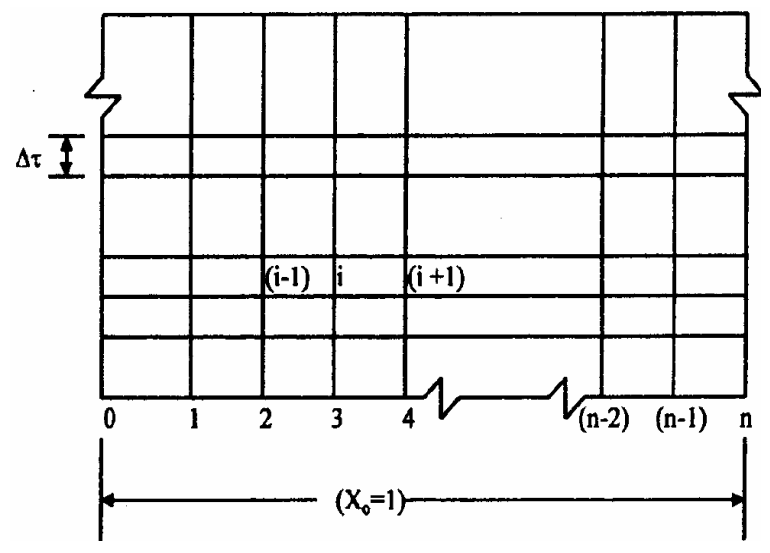

Fig. 2: The mesh of time and space intervals during the finite difference solutions
$E(j)=\frac{1}{m} \sqrt{\sum_{i=1}^{m}\left(T_{e}(i)-T_{p}(i)\right)^{2}}$

where, $\mathrm{j}=0,1,2,3,4$ whereas, $\mathrm{T}_{\mathrm{e}}, \mathrm{T}_{\mathrm{p}}$ are experimental and computed temperatures respectively and $\mathrm{m}$ is the number of data points

\section{RESULTS AND DISCUSSION}

A program was developed (visual FORTRAN) for the system of $\mathrm{Eq} \mathrm{(1-16)} \mathrm{to} \mathrm{predict} \mathrm{the} \mathrm{temperature}$ distributions versus time at five locations inside the food sample, so as to compare the computed values with the experimental results as shown in Fig. 3. For the stability consideration in the explicit finite difference scheme, $\Delta \mathrm{t}$ was chosen to be equal to $(\Delta \mathrm{X})^{2} / 6^{[10]}$. The program was repeated run many times for all the possible finite difference schemes to establish a scheme which is accurate, reliable and efficient for heat transfer analyses during precooling of infinite slabs. Calculations were repeated for different values of weighing factor $(\theta)$ from 0 to 1 in step of 0.2 . During all the calculations, higher deviations between computed and measured temperatures were observed for some initial time. Thorough investigations revealed that the variation continued to occur until $\tau>0.2$ on all samples, for all the values of $\theta$ and $n$. Fig. 4 shows the optimum value of $\theta$ with constant $\mathrm{n}$ that yields minimum computational time and high accuracy of the sensor locations starting from the center of the slab, E $(0)$, toward the surface of the sample at five equidistant locations. It was observed that up to $\mathrm{X}=0.6$, there was little deviation between the measured and computed temperatures. But beyond this, the deviation was sufficiently high. It was interesting to note that the simple explicit finite difference scheme yielded temperatures, which were consistently in good agreement with measured values. The computational time for the implicit finite difference scheme, using $\mathrm{n}=$ 45 was 36 times more than that for the explicit scheme and accuracy was also slightly impaired. The same trend persisted for higher values of $n$. The error value at any sensor location decreased very slightly with $\mathrm{n}$ and the minimal one was obtained from the sensor fixed at the center, whereas the error increased with the sensor distance from the center of the infinite slab. Figure 5 shows the variation of error with $\mathrm{n}$ for fully explicit, fully implicit and Crank Nicolson schemes.

The minimal error could be obtained with $\mathrm{n}=10$ for all the schemes investigated. All the schemes yielded the same value of error in the range of $10 \leq n \leq 45$. Beyond this range, the implicit scheme was found to be slightly more accurate than the explicit scheme at the cost of much increased computational time. The CrankNicolson Scheme was found to be less accurate for the present set of equations. 


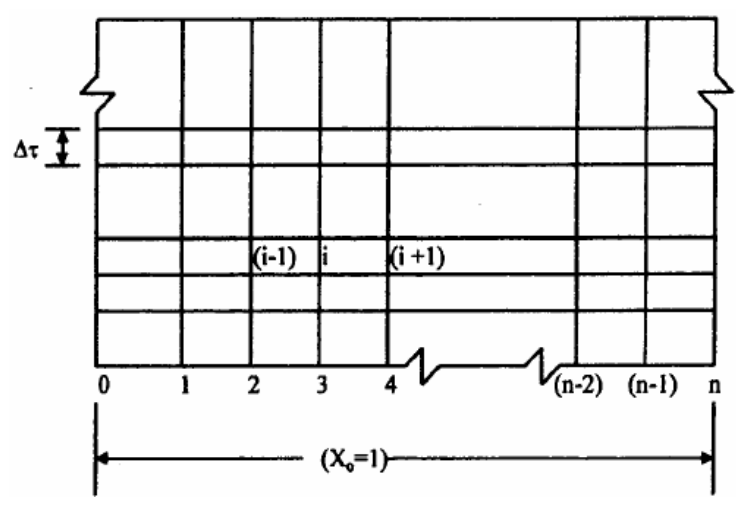

Fig. 3: Comparison of computed and measured temperatures at the center of a slab

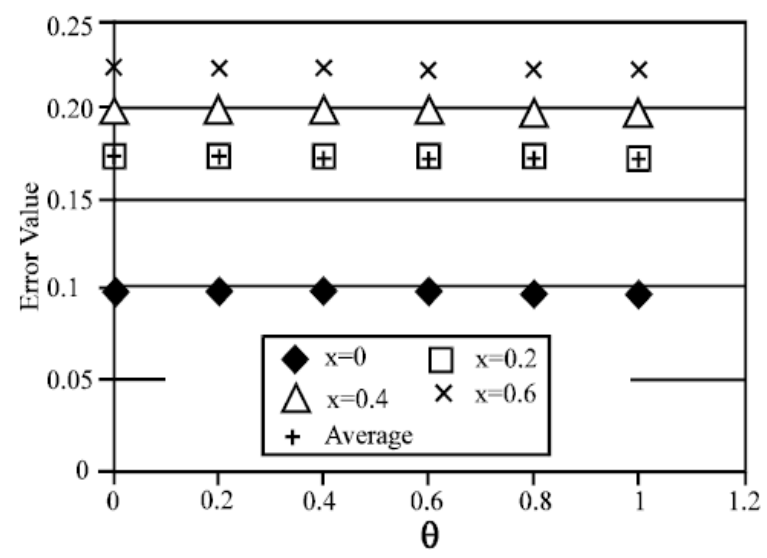

Fig. 4: Error distribution throughout the sample

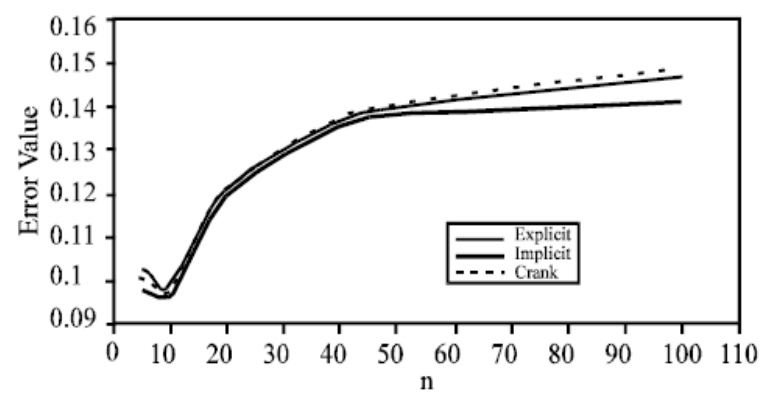

Fig. 5: Comparison of computational error

\section{CONCLUSIONS}

On the basis of thorough numerical and experimental investigations performed in the present work by the explicit finite difference scheme, implicit finite difference scheme and implicit explicit finite difference schemes with varying weighing factors, it can be concluded that:

- As $n$ increases from 5 to 10 the accuracy increases and beyond that the computational accuracy will be least affected
- For $\mathrm{n}=45$, the computation time increases 36 times for the implicit scheme compared to that scheme while computational error decreased very slightly

- The computational error increases as we approach nearer to the surface of the sample. For $\mathrm{X}>0.6$, the computational error is on the higher side

- All the finite difference schemes were found to yield reasonably accurate and reliable results for 0 $\leq \mathrm{X} \leq 0.6, \mathrm{n}=10$ and $\mathrm{t}>0.2$

- The simple explicit finite difference scheme with $\mathrm{n}$ $=10$ and $\Delta \tau=(\Delta X)^{2} / 6$ gives the most reliable and accurate results for making thorough heat transfer analyses during air blast precooling of an infinite slab shaped packages of

- Fresh water Pangasius Sutchi Malaysian fish. It may be recommended for temperature calculations

\section{ACKNOWLEDGEMENT}

The present work was funded through the internal research funding of the Multimedia University, Malaysia (MMU), which is thankfully acknowledged. The authors also acknowledge the experimental and computational facilities provided by the MMU. During the course of work, the teaching and technical staff of the Faculty of Food Sciences in the University Putra Malaysia has been ever ready to assist and provide all sorts of help. All their encouragement and help is thankfully acknowledged.

\section{NOTATION}

Bi Biot number (h. xo/ $/ \mathrm{k}_{\mathrm{fish}}$ )

$\mathrm{E}$ error value at any temperature sensor location

$\mathrm{h}$ surface film conductance $\left(\mathrm{W} / \mathrm{m}^{2} . \mathrm{K}\right)$

$\mathrm{k}$ thermal conductivity of product $(\mathrm{W} / \mathrm{m} . \mathrm{K})$

$\mathrm{Nu}$ Nusselt number (h. xo/ $\left.\mathrm{k}_{\text {air }}\right)$

Pr Prandtle number $\left(\mu . \mathrm{cp} / \mathrm{k}_{\mathrm{air}}\right)$

$\operatorname{Re}$ Reynolds number $\left(\rho, \mathrm{V} . \mathrm{x}_{\mathrm{o}} / \mu\right)$

$\mathrm{t}$ time (s)

$\mathrm{T}$ temperature $\left({ }^{\circ} \mathrm{C}\right)$

$\mathrm{T}_{\mathrm{db}}$ dry bulb temperature of chilled air $\left({ }^{\circ} \mathrm{C}\right)$

$\mathrm{T}_{\mathrm{cm}}$ cooling medium temperature $\left({ }^{\circ} \mathrm{C}\right)$

$\mathrm{T}_{\mathrm{i}}$ initial product temperature $\left({ }^{\circ} \mathrm{C}\right)$

$\mathrm{U}$ dimensionless temperature $\left[\left(\mathrm{T}-\mathrm{T}_{\mathrm{cm}}\right) /\left(\mathrm{T}_{\mathrm{i}}-\mathrm{T}_{\mathrm{cm}}\right)\right]$

$\mathrm{x}$ distance from center $(\mathrm{m})$

$\mathrm{X}$ dimensionless space coordinates $\left(\mathrm{x} / \mathrm{x}_{0}\right)$

$\mathrm{x}_{0}$ half thickness of infinite slab

$\tau$ Fourier number $\left(\alpha . t / \mathrm{x}_{0}{ }^{2}\right)$

$\alpha$ Thermal diffusivity of product $\left(\mathrm{m}^{2} / \mathrm{s}\right)$

\section{REFERENCES}

1. Ansari, F.A., 1984. Heat and Mass Transfer Analysis in Cold Preservation of Food. Ph.D. Thesis, University of Roorkee, India. 
2. Mohsin, A.K.M. and M. A. Ambak, 1980. Freshwater Fishes of Peninsular Malaysia. University Pertanian Malaysia.

3. Hasimah, H.A., 2003. Personal communication with Malaysian Agricultural Research and Development Institute. Food Technology Centre.

4. Baird, C.D. and J.J. Gaffney, 1976. A numerical procedure for calculating heat transfer in bulk loads of fruits and vegetables. Transactions. Am. Soc. Heating Refrigerating and Air-conditioning Engineers, 82: 525-40.

5. Gaffney, J.J., C.D. Baird and K.V. Chau, 1985. Methods for calculating heat and mass transfer in fruits and vegetables individually and in bulk. Transactions. Am. Soc. Heating Refrigerating and Air-conditioning Engineers, 91: 333-352.

6. Hayakawa, K.I. and J. Succar, 1982. Heat transfer and moisture loss of spherical fresh produce. J. Food Sci., 47: 595-605.

7. Hayakawa, K. I., 1978. Computerized simulation for heat transfer and moisture loss from an idealized fresh produce. Transactions. Am. Soc. Agri. Engineers, 21: pp. 1015

8. Hayakawa, K.I., 1982. A new method for the computerized determination of the apparent thermal diffusivity of food. Proceedings. First Pacific Chemical Engineering Congress, Part II, pp: 129.

9. Richtmyer, R.D. and K.W. Morton, 1967. Difference Methods for Initial Value Problems. Second Edition (Tracts in Mathematics Number 4). New York, Inter science Publishers.
10. Crank, J. and P.A. Nicolson, 1947. Practical Method for Numerical Evaluation of Partial Differential equations of Heat Conduction Type. Proceedings, Phil. Soc., 43: 50.

11. Smith, G.D., 1965. Numerical Solution of Partial Differential Equations with Exercises and Worked Solutions. Oxford University Press, London.

12. Narayanan, B.K., 1976. Heat and Mass Transfer Studies and Evaluation of Thermal Properties of Food Products. PH. D. Thesis, Indian Institute of Technology, Madras, India.

13. Berezin, I.S. and M.P. Zhidkov, 1965. Computing Methods, Addison Wesley Publishing Company Inc., Reading, Mass., 1: 210.

14. Sweat, V.E., 1975. Modelling the thermal conductivity of meats, Transaction of ASAE, 18: 564-568.

15. Sudhaharini, R., 1998. Measurement of Thermal Properties of Seafood. M.Sc. Thesis, Virginia Polytechnic Institute and State University.

16. Ansari, F.A., M.A. Wan and KA. Abbas, 2003. An improved scheme for temperature calculations in food. Energy Conversion and Management, 44: 2373-2382. 